\title{
Current stocking program of the sterlet (Acipenser ruthenus, L.) can negatively shape its genetic variability in the Middle Danube
}

\author{
Ladislav Pekárik ${ }^{1,2,{ }^{*}}$, Zuzana Čiamporová-Zat'ovičová ${ }^{1}$, Darina Arendt ${ }^{1}$, Fedor Čiampor, $\mathrm{Jr}^{1}$ \\ ${ }^{1}$ Zoology Lab, Plant Science and Biodiversity Center, Dúbravská Cesta 9, Bratislava 84523, Slovakia \\ ${ }^{2}$ Faculty of Education, Trnava University, Priemyselná 4, PO Box 9, Trnava 91843, Slovakia
}

\begin{abstract}
The Danube River was originally inhabited by six native sturgeon species, but currently, the sterlet (Acipenser ruthenus L.) is the only native sturgeon species still occupying the Slovak-Hungarian stretch of the Middle Danube. All sturgeon species are facing extinction, suffering from overfishing, water pollution, illegal fishing, poaching or other negative impacts. Urgent and proper actions are needed to prevent their extinction, and evaluating its genetic diversity is one of the essential tools of conservation programs. Since the management actions are primarily local in nature, we first focused on comparing and analysing local sources of fish for population recovery and natural (wild) population in the adjacent stretch of the Danube River. We used 2 fragments of mitochondrial DNA and 12 microsatellites to analyse the genotype of the three groups of sterlets, i.e. wild, broodstock and stocked individuals from Slovak part of the Danube. Mitochondrial markers of all groups were diversified similarly to populations from other parts of the Danube. This confirmed that broodstock and stocked fish belong to the original Danube population. Microsatellites revealed very similar patterns among groups compared, but we detected possible negative trends reflected in losing polymorphism in a few loci in broodstock and stocked individuals.
\end{abstract}

Keywords: starlet / genetic diversity / stocking management / Middle Danube

\begin{abstract}
Résumé - Le programme actuel d'empoissonnement du sterlet (Acipenser ruthenus, L.) peut influencer négativement sa variabilité génétique dans le Danube moyen. Le Danube était à l'origine peuplé de six espèces d'esturgeons indigènes, mais à l'heure actuelle, le sterlet (Acipenser ruthenus L.) est la seule espèce d'esturgeon indigène qui occupe encore la partie slovaque-hongroise du Danube moyen. Toutes les espèces d'esturgeons sont menacées d'extinction, souffrant de surpêche, de pollution des eaux, de pêche illégale, de braconnage ou d'autres impacts négatifs. Des mesures urgentes et appropriées sont nécessaires pour prévenir leur extinction, et l'évaluation de leur diversité génétique est l'un des outils essentiels des programmes de conservation. Comme les mesures de gestion sont principalement de nature locale, nous nous sommes d'abord concentrés sur la comparaison et l'analyse des sources locales de poissons pour le rétablissement de la population et de la population naturelle (sauvage) dans le tronçon adjacent du Danube. Nous avons utilisé deux fragments d'ADN mitochondrial et douze microsatellites pour analyser le génotype des trois groupes de sterlets, c'est-à-dire des individus sauvages, des géniteurs en pisciculture et des individus déversés dans la partie slovaque du Danube. Les marqueurs mitochondriaux de tous les groupes étaient diversifiés de la même façon que les populations d'autres parties du Danube. Cela a confirmé que les géniteurs et les poissons d'élevage appartiennent à la population originale du Danube. Les microsatellites ont révélé des tendances très semblables parmi les groupes comparés, mais nous avons décelé des tendances négatives possibles se traduisant par une perte de polymorphisme dans quelques loci chez les géniteurs et les individus déversés.
\end{abstract}

Mots-clés : sterlet / diversité génétique / gestion de la conservation / Danube moyen

\footnotetext{
*Corresponding author: ladislav.pekarik@savba.sk
} 


\section{Introduction}

Historically, six native sturgeon species were reported from the Danube River (Reinartz, 2002). After the migration route was closed by Iron Gate dams I and II in 1972, only three species, the sterlet (Acipenser ruthenus, L.), the Russian sturgeon (Acipenser gueldenstaedtii, Brandt, 1833) and the ship sturgeon (Acipenser nudiventris, Lovetsky, 1828) were recorded in the Middle Danube (Holčík, 1989). At the beginning of the twenty-first century, two remaining species, the sterlet and the Russian sturgeon, were present in the Slovak-Hungarian stretch of the Middle Danube (Holčík et al., 2006). Currently, the sterlet is the last native sturgeon species still regularly occupying the Slovak-Hungarian stretch of the Middle Danube (see Friedrich, 2018 for details).

A considerable decrease of the sterlet population was observed in the Middle Danube from the beginning of the twenty-first century (Guti and Gaebele, 2009). Although a significant effort in the sterlet artificial propagation by extensive stocking was made, and in the first years, the sterlet population seemed to recuperate (Reinartz, 2002), the population is fluctuating, but the trend is still decreasing. The irregular stocking program started in 1989 in Slovakia (Holčík et al., 2002). Since the beginning of the twenty-first century, the stocking program is regular and several thousands (up to ten thousands) of fingerlings are stocked every year (data provided by Slovak Angler's Union). Stocked sterlets are of Danubian origin from the Slovak-Hungarian Danube section. The efficiency of the past stocking was more or less unknown until the last few years. A sample of the stocked individuals consisting of 1270 individuals was tagged with FLOY tags during 2013-2016. The ratio of recaptures was very low, two individuals were recaptured few weeks after stocking and one tag was found in the stomach of the wels (Silurus glanis, L.) about 1 month after stocking (Kubala et al., 2017). Furthermore, ageing of the sterlet population seems apparent in recent years. The average weight of sterlet catches reported by the Slovak Angler's Union is increasing from $2.0-2.5 \mathrm{~kg}$ during 2003-2007 to $3.0-4.0 \mathrm{~kg}$ during 2011-2016, which could be caused by missing younger classes.

The genetic variability analyses of the sterlet broodstock and stocked individuals, emphasizing management purposes, are almost absent. If specimens from the aquaculture are genetically analysed, they are usually included in larger phylogeographic studies (e.g. Zhang et al., 2013). Fish species with high fecundity can produce a high number of offspring originating from only a few individuals. Sturgeon fecundity is very high (Holčík, 1989), and thus drift-associated alterations could result in a bottleneck effect and negatively influence the shaping of the population genetic variability. Subsequently, the effective population size is prone to decline below critical threshold values. This reduction could result in the rapid loss of rare alleles and in other drift-associated changes in the frequencies of selectively neutral alleles, as well as in reducing polygenic variability (Tringali and Bert, 1998). Since the information on the genetic diversity is one of the essential tools in conservation programs, the main aim of this study was to assess the genetic identity and structure of the wild, broodstock and stocked individuals from the Slovak part of the Danube, compare their genetic diversity and provide the recommendation for the future stocking management.

\section{Material and methods}

\subsection{Sampling}

Eleven wild sterlets sampled in the Slovak-Hungarian stretch of the Danube river at river km 1714-1717 in 2016 (WILD group; W01-W11) were analysed as referenced wild samples. Thirty F1 individuals from the broodstock with a presumably Danubian origin (F1 group; F01-F30) and 10 stocked individuals used in the stocking program in 2016 (STOCK group; S01-S10) (Tab. S1) were included in the analyses. The broodstock (F1) and parents of the stocked individuals (STOCK) used in Slovakia were of the same Middle Danube origin. Originally they were kept together, but later they were divided into two groups belonging to two different owners. Lower sample number is mainly due to the low abundance of sterlets in the studied part of the Danube, but the size of the dataset is comparable with other sterlet studies (e.g. Doukakis et al., 1999; Dudu et al., 2013; Chassaing et al., 2016). Ventral fin clips were taken non-lethally, and the fish were released back to the river immediately after sampling. Tissue samples were preserved in $99.9 \%$ ethanol and stored at $-25^{\circ} \mathrm{C}$.

\subsection{Laboratory procedures}

Genomic DNA was extracted using standard extraction kit (DNeasy Blood and Tissue kit, QIAGEN, The Netherlands) following manufacturer's protocol. Vouchers and extracted DNA are stored at the author's institution.

Two mitochondrial markers were used to assess the genetic identity and genetic structure of three target sterlet groups. Partial cytochrome b (CYTB; 1100 bp fragment) was amplified using L15267 and H16526 primers (Briolay et al., 1998) and partial cytochrome c oxidase I (COI; $686 \mathrm{bp}$ fragment) was amplified using FF2d and FR1d primers (Ivanova et al., 2007). Polymerase chain reactions (PCR) were conducted in $25 \mu \mathrm{l}$ total volume using DreamTaq ${ }^{\mathrm{TM}}$ DNA Polymerase (Promega), containing $1 \mu \mathrm{l}$ of DNA template, set up as follows: $2^{\prime}$ initial denaturation at $94^{\circ} \mathrm{C}, 35$ cycles $\left(94^{\circ} \mathrm{C}\right.$ for $30^{\prime \prime}, 48^{\circ} \mathrm{C}$ for $40^{\prime \prime}$, $72^{\circ} \mathrm{C}$ for $\left.40^{\prime \prime}\right), 10^{\prime}$ final extension at $72^{\circ} \mathrm{C}$. For electrophoresis $5 \mu \mathrm{l}$ of PCR products was used (1\% agarose gel) to check amplification and remaining volume was purified using exonuclease I and alkaline phosphatase (Werle et al., 1994). Sequencing of successfully amplified PCR products was performed in a commercial laboratory (Macrogen Europe, Inc., Amsterdam, The Netherlands).

Microsatellites were used to compare the genetic diversity of sterlet target groups. Twelve pairs of most frequently used microsatellite primers were tested on several individuals of $A$. ruthenus. Four loci were originally developed for lake sturgeon (LS19, LS34, LS54, LS39-; May et al., 1997), six for Gulf sturgeon (Aox9, Aox12, Aox23, Aox27, Aox45-; King et al., 2001; AoxD234-; Henderson-Arzapalo and King, 2002) and two for Adriatic sturgeon (AnacE4, AnacC11-; Forlani et al., 2008). The short M13 sequence (CACGACGTTGTAAAACGAC) was added to the more suitable primer based on 

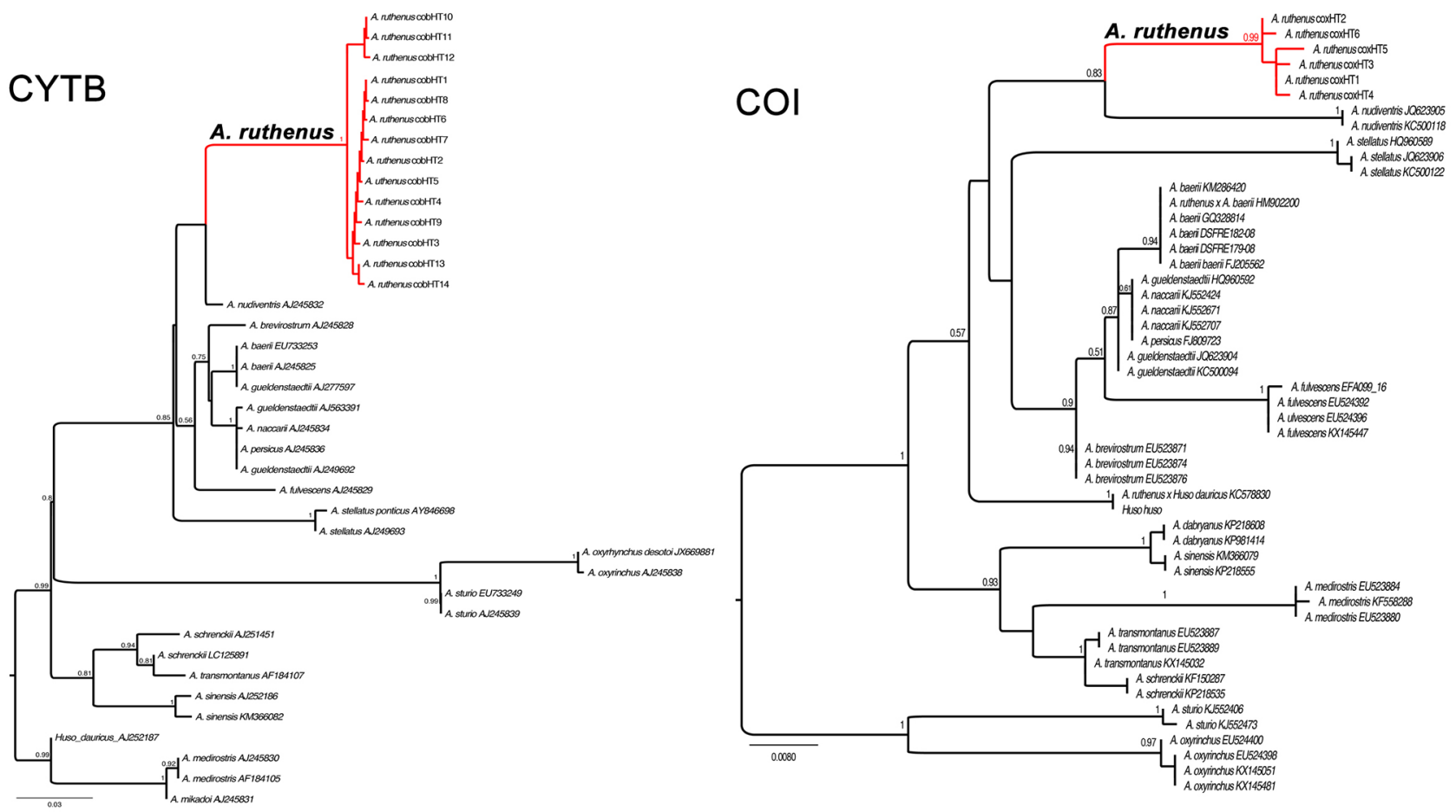

Fig. 1. Maximum likelihood trees based on two mtDNA fragments of Acipenser and Huso samples (new sequences produced within this study and GenBank and BOLD samples of A. ruthenus and other Acipenser and Huso species). Numbers next to nodes represent Bootstrap values. A. ruthenus clade is represented by the detected haplotypes, for the complete list of samples see Supplementary Table S2.

evaluation for primer melting temperature and primer secondary structure in NetPrimer (http://www.premierbio soft.com/netprimer/netprimer.html). The best annealing temperatures were assessed by gradient PCR on several samples (PCR conditions were the same as mentioned below except annealing temperature range: $45-69^{\circ} \mathrm{C}$ ), and the amplification products were visualized on $2 \%$ agarose gel to check whether they contain microsatellites. Subsequently, the variability of loci was analysed on LI-COR 4300 DNA Analyzer (LI-COR Biosciences) using the length of alleles. PCR's were performed for all collected samples using Eppendorf Mastercycler and DreamTaq ${ }^{\mathrm{TM}}$ DNA polymerase (Promega) for a total volume of $10 \mu \mathrm{l}$, comprising ca. $50 \mathrm{ng}$ genomic DNA, $1 \mu \mathrm{l}$ Dream$\mathrm{Taq}^{\mathrm{TM}}$ Buffer, $0.6 \mu \mathrm{l}$ of $\mathrm{Mg}^{2+}(25 \mathrm{mM}), 0.2 \mu$ l of dNTP Mix $(10 \mathrm{mM}), 0.5 \mu \mathrm{l}$ of $1.0 \mathrm{pmol} \cdot \mu \mathrm{l}-1$ labelled and unlabelled primers, $0.33 \mu \mathrm{l}$ of $1.0 \mathrm{pmol} \cdot \mu \mathrm{l}-1 \mathrm{LI}-\mathrm{COR}^{\circledR} 700$ or 800 IRDlabelled M13 Primer (LI-COR Biosciences), $0.05 \mu 1$ (0.625 U) DreamTaq $^{\mathrm{TM}}$ DNA polymerase and nuclease-free water to $10 \mu \mathrm{l}$. The PCR conditions were as follows: initial denaturation at $94^{\circ} \mathrm{C}$ for $5^{\prime}, 35$ cycles of $94^{\circ} \mathrm{C}$ for $30^{\prime \prime}, 56-58^{\circ} \mathrm{C}$ for $30^{\prime \prime}, 72^{\circ} \mathrm{C}$ for $45^{\prime \prime}$ and final elongation at $72^{\circ} \mathrm{C}$ for $10^{\prime}$. The denatured PCR products were electrophoresed on $6.5 \% \mathrm{~KB}$ Plus polyacrylamide gel in LI-COR 4300 DNA Analyzer (LI-COR Biosciences).

\subsection{Genetic and statistical analysis}

Sequences of CYTB and COI mitochondrial fragments were edited in Sequencher 5.1 (Gene Codes). All variable positions were checked on chromatographs, and unreliable samples were discarded. Alignments, final matrix, substitution model selection, maximum likelihood (ML) trees and Bootstrap support (1000 replicates) were completed using MEGA 6.06 (Tamura et al., 2013). Trees were finalised in FigTree v1.4.2. To examine haplotypes relationships, a median-joining network (MJN) was constructed in PopART (Leigh and Bryant, 2015). Origin of each specimen carrying a given haplotype was colour-coded to illustrate haplotype distribution among groups analysed. Diversity indices were calculated in DNAsp 5.0 (Librado and Rozas, 2009). The analyses of concatenated data were not performed due to different datasets of samples representing remaining sturgeon species. All sequences were sent to GenBank and the Barcode of Life Data System (BOLD). Accession numbers, BOLD process IDs and BINs for COI are listed in Table S1. The whole dataset is available in dx.doi.org/10.5883/DS-SKACIRUT.

Additional public CYTB (7) and COI (15) sequences of A. ruthenus from different localities, as well as sequences representing other Acipenser species, were downloaded from GenBank and BOLD and included in analyses.

Microsatellite data were tested for the potential presence of genotyping errors, null alleles and allelic dropouts in MicroChecker v2.2.3 (Van Oosterhout et al., 2004). Allele frequency, Shannon's Information index, observed and expected heterozygosities, inbreeding index and test for linkage disequilibrium were calculated in GenAlEx (Peakall and Smouse, 2006) and Arlequin v3.5.1.2 (Excoffier et al., 2005), with 1000 permutations. Model-based Bayesian clustering modelling method implemented in STRUCTURE software v.2.3 (Pritchard et al., 2000) was used to examine the 

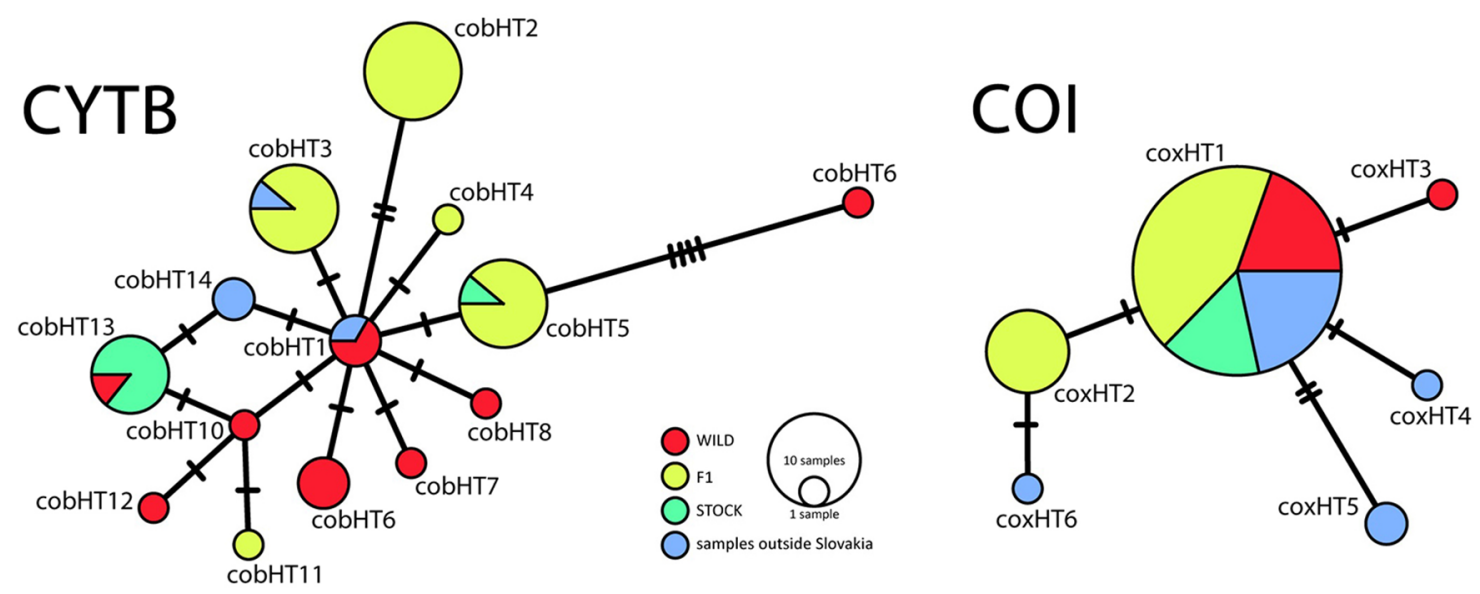

Fig. 2. Haplotype networks (MJN) based on two mtDNA fragments. Red, yellow and green colours represent samples from Slovakia, blue includes samples from other countries.

most likely number of distinct genetic clusters $(\mathrm{K})$ in the dataset. The program was run for $K=1-10$, assuming a model of admixture and correlated allele frequencies with the LOCPRIOR setting. The LOCPRIOR setting was used to detect structure by providing priors for the Bayesian assignment process based on the belonging to individual groups (W, F, S) (Hubisz et al., 2009). Monte Carlo Markov Chain was run with 500,000 replications after a burn-in of 50,000 iterations. The most likely number of clusters was determined with the Evanno method (Evanno et al., 2005) using STRUCTURE Harvester for visualizing outputs (Earl and vonHoldt, 2012). Non-model-based modelling by Discriminant Analysis of Principal Components (DAPC) was used to propose an optimum distribution of individuals into predefined groups in relation to the discriminant function of principal components. $\mathrm{R}$ statistical environment ( $\mathrm{R}$ Core Team, 2017) and the adegenet package were used for DAPC (Jombart and Ahmed, 2011).

\section{Results}

\subsection{Analysis of mtDNA data}

All available sequences of $A$. ruthenus (CYTB - 51, COI - 64) and samples representing the remaining Acipenser species were used in the analyses. Both mitochondrial fragments grouped $A$. ruthenus samples in a well-delimited cluster with high support, confirming their utility for species determination (Fig. 1). The remaining species, with few exceptions, were also well recognized. Few hybrids were included in the $A$. ruthenus cluster, suggesting that their female parent belonged to $A$. ruthenus.

Within CYTB fragments, 14 haplotypes were detected (13 in Slovak samples), and were differentiated by one to four mutation steps (Fig. 2). Nucleotide diversity was low (Pi: 0.0024), haplotype diversity was higher (Hd: 0.878). The samples were relatively evenly distributed among haplotypes, only three (cobHT3, cobHT5, cobHT13) exceeded a frequency of $10 \%$ and cobHT11 was the most frequent
(21.6\%). Analysis of COI fragments revealed much lower diversity (Pi: 0.00076, Hd: 0.353). Only six haplotypes were detected (three in Slovakia), separated by one to two mutations. Almost $80 \%$ of the samples (51) belonged to coxHT1, and the remaining haplotypes were much less frequent (Tab. S2). Regarding samples collected in Slovakia, the most diversified was the WILD group, represented by eight CYTB haplotypes or two COI haplotypes. The F1 group was represented by five CYTB haplotypes and two COI haplotypes; the lowest diversity was recorded in the STOCK group (one haplotype for each fragment). As suggested by ML analysis, haplotype networks confirmed close relationships of the samples from Slovakia with those from other regions of the species distribution (Fig. 2). Both groups, i.e. Slovak samples and remaining ones, shared two CYTB haplotypes and one COI haplotype.

\subsection{Microsatellites}

Among 12 microsatellite primer pairs tested, we obtained reproducible amplification for 6 loci (LS19, LS34, LS39, LS54, Aox27, Aox45). Among these six loci, five showed polymorphism and were used in analyses, while one was monomorphic (LS54). MicroChecker revealed no signs of large allele dropout, stuttering at any locus, or presence of a null allele. Altogether, 23 alleles were identified, 20 alleles for the F1 group, 18 alleles for the WILD group and 16 alleles for the STOCK group (F1 group included more samples). The highest percentage of polymorphic alleles was in the WILD group (100\%) with $P$-value 1 for all microsatellites (Tab. 1). A pattern of allelic loss was observed within the F1 group (80\% polymorphic) and STOCK group (60\% polymorphic). Bayesian clustering analysis indicated one uniform group with weak shifts among WILD (2), F1 (3) and STOCK (1) groups (Fig. 3). DAPC indicates one group with visible trends in its separation into WILD, F1 and STOCK groups (Fig. 4). Separation of the groups can be supported by the probability of the group identity with the majority of individuals belonging to the a priori defined group. 
Table 1. Characteristics of the microsatellite loci for 3 sterlet (Acipenser ruthenus) groups. $\mathrm{N}$ - number of individuals; $\mathrm{Na}-$ number of detected alleles; Ne - number of effective alleles; I - Shannon's Information Index; Ho - observed heterozygosity; He - expected heterozygosity; Fis inbreeding index; $\mathrm{S}-$ stock; $\mathrm{W}$ - wild.

\begin{tabular}{|c|c|c|c|c|c|c|c|c|c|c|}
\hline Pop & Locus & $\mathrm{N}$ & $\mathrm{Na}$ & Size range (bp) & $\mathrm{Ne}$ & I & Ho & $\mathrm{He}$ & $P$-value & Fis \\
\hline \multirow[t]{5}{*}{ S } & LS19 & 10 & 1 & 136 & 1.000 & Monomorphic & & & & \\
\hline & LS34 & 10 & 4 & $142-154$ & 1.370 & 0.588 & 0.300 & 0.284 & 1.000 & -0.111 \\
\hline & LS39 & 10 & 3 & $111-126$ & 2.198 & 0.856 & 0.800 & 0.574 & 0.199 & -0.468 \\
\hline & Aox 27 & 10 & 1 & 114 & 1.000 & Monomorphic & & & & \\
\hline & Aox 45 & 10 & 7 & $121-145$ & 4.444 & 1.678 & 1.000 & 0.816 & 0.678 & -0.290 \\
\hline \multirow[t]{5}{*}{ W } & LS19 & 11 & 2 & $136-139$ & 1.308 & 0.398 & 0.273 & 0.247 & 1.000 & -0.158 \\
\hline & LS34 & 11 & 3 & $142-154$ & 1.754 & 0.760 & 0.545 & 0.450 & 1.000 & -0.269 \\
\hline & LS39 & 9 & 3 & $123-129$ & 2.418 & 0.958 & 0.667 & 0.621 & 1.000 & -0.137 \\
\hline & Aox 27 & 11 & 2 & $114-118$ & 1.095 & 0.185 & 0.091 & 0.091 & 1.000 & -0.048 \\
\hline & Aox 45 & 10 & 8 & $121-145$ & 6.667 & 1.973 & 1.000 & 0.895 & 1.000 & -0.176 \\
\hline \multirow[t]{5}{*}{$\mathrm{F} 1$} & LS19 & 30 & 1 & 136 & 1.000 & Monomorphic & & & & \\
\hline & LS34 & 30 & 4 & $139-154$ & 1.703 & 0.810 & 0.467 & 0.420 & 0.401 & -0.131 \\
\hline & LS39 & 28 & 3 & $111-126$ & 2.212 & 0.884 & 0.607 & 0.558 & 0.374 & -0.108 \\
\hline & Aox 27 & 30 & 2 & $114-118$ & 1.034 & 0.085 & 0.033 & 0.033 & 1.000 & -0.017 \\
\hline & Aox 45 & 29 & 10 & $121-151$ & 8.286 & 2.204 & 0.966 & 0.895 & 0.011 & -0.098 \\
\hline
\end{tabular}

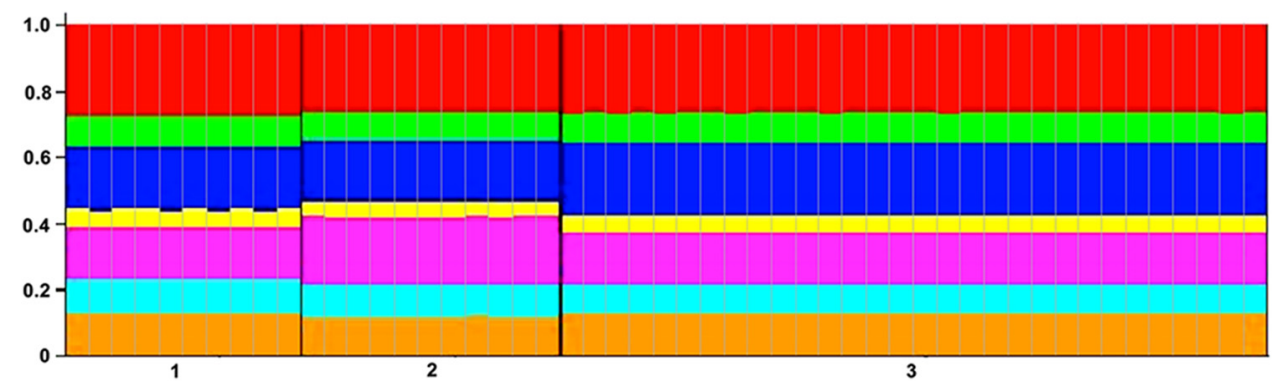

Fig. 3. Results of the Bayesian clustering analysis for Acipenser ruthenus samples from Slovakia. Each bar represents a single individual, colours represent genetic clusters; sterlet groups: 1 - stock, 2 - wild, 3 - F1.

\section{Discussion}

Stocking programs are widely used tools to manage populations of the target fish species, and it has been a common practice for more than a century in Europe. In the past, its main goal was to strengthen fish populations for recreational fishing. In recent decades, considering the genetic characteristics of the broodstock or stocked individuals became a common practice worldwide due to the potential impact on the local wild populations. The two most commonly controlled attributes are the origin of the released fish and their genetic composition. Such information is even more important in stocking programs of endangered species, where the impacts could be much higher.

In this work, we first focused on the comparison of the genetic variability of the kept sterlets from breeding facilities and wild population of the adjacent part of the large river (Slovak-Hungarian stretch of Danube) where these fish are stocked. Since restocking activities are often local in nature, the results of this study may have a direct and practical impact on management actions. It should include a coordinated basinwide stocking program and use more diversified broodstocks supplemented by wild individuals. Analyses of mitochondrial and nuclear markers from wild fish, broodstock and stocked individuals uncovered their Danubian origin and differences in

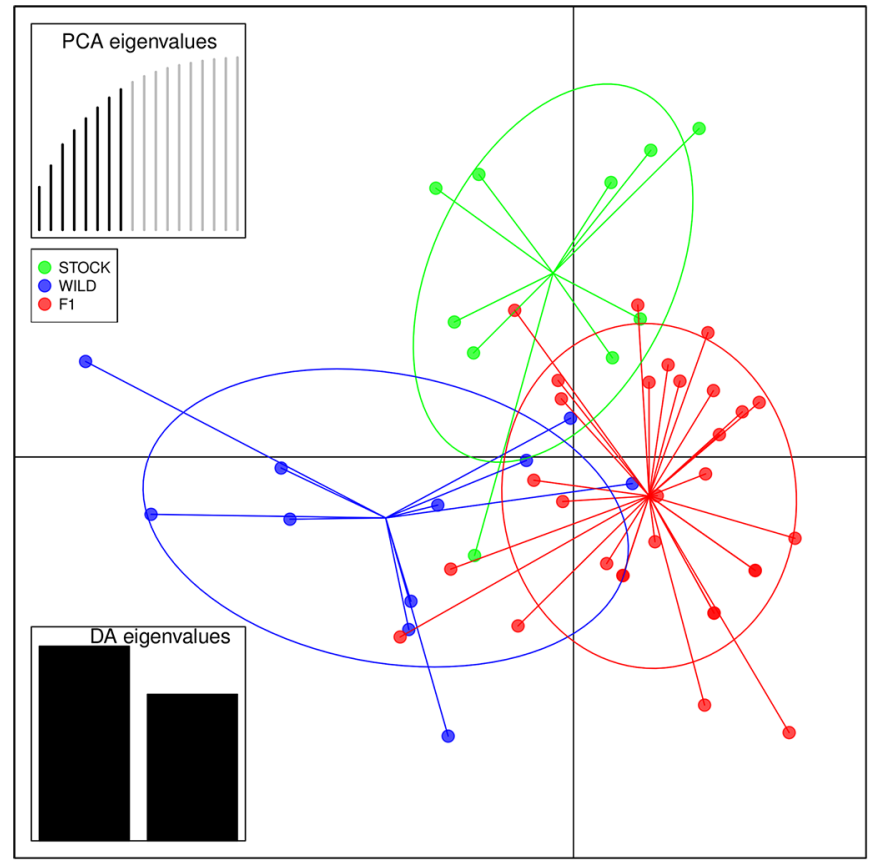

Fig. 4. Discriminant analysis of principal components of microsatellite data of the three studied A. ruthenus groups. 
the genetic structure of the groups. MtDNA samples were analysed together with known data from other sturgeon species. Barcoding fragment (COI) showed high reliability concerning sample determination (Fig. 1). Previously, various phylogenetic reconstructions were published, proposing relationships of A. ruthenus with Huso dauricus or A. stellatus (e.g. Birstein and DeSalle, 1998; Zhang et al., 2013). Our results, based on both fragments (CYTB, COI), support close relationship between $A$. ruthenus and $A$. nudiventris, corresponding with findings of Ludwig et al. (2001) or Mugue et al. (2016). Both the mitochondrial fragments were highly reliable regarding species delimitation, and we can conclude that wild, broodstock and stocked fish are of the same origin, most likely from the Middle Danube. The only unresolved group was detected when CYTB was used, including $A$. baeri, $A$. gueldenstaedtii, $A$. persicus and $A$. naccarii. This was likely caused by their very close relationships and low resolution of shorter fragments. Barcoding fragment (COI) revealed highly congruent results with an analysis of the whole mitogenome (Mugue et al., 2016).

Both mitochondrial fragments were also important in estimating the genetic (nucleotide, haplotype) diversity within groups. Genetic diversity is a central concept of evolutionary biology that is linked to the organismal complexity and a species ability to respond to environmental changes (e.g. O'Brien, 1994; Lynch and Conery, 2003). The lack of diversity is typically considered as evidence for a small or endangered population (Amos and Balmford, 2001; Pauls et al., 2013). Such decline in genetic diversity can be caused by direct human action, which can lead to undesirable bottleneck effects that could gradually reduce the ability of individuals to adapt to and overcome environmental changes (Leberg and Firmin, 2008). Overall, the recovered mitochondrial diversity of sterlet population in the Middle Danube (Slovak-Hungarian stretch) is comparable with other parts of the river (e.g. Reinartz et al., 2011; Cvijanović et al., 2015), but within three groups, particularly for the more variable CYTB, a notable difference in the number of haplotypes was observed (W - 8, F1 - 5, $\mathrm{S}-2$ ). Although with almost the lowest size, the WILD group had the highest number of haplotypes. The lowest number of haplotypes was recorded in the STOCK group, which was also confirmed by the more conservative COI. This could be due to the insufficient interchange of individuals used within the restocking management, and it can represent the first warning sign suggesting a decline in the genetic diversity between the groups. Although the WILD group reached the highest genetic diversity, it still likely represents only a small fraction of the original variability as a result of the past population decline (Chassaing et al., 2016). This was seen also on the low number of the caught individuals. In order to preserve or improve the genetic diversity of sterlets in the Middle Danube, it will be very important to ensure that genetic diversity of released fish is taken into account in restocking management, most preferably by using fish from different sources of the original Danube population.

In addition, mtDNA fragments were compared with allele frequencies of microsatellite markers. Although the number of polymorphic microsatellite loci with reproducible amplification seems to be low, sufficient information about the genetic diversity could be obtained. The same or even lower number of loci was used in several other studies (Jug et al., 2005; Crispo and Chapman, 2008; Horne et al., 2011; Elbrecht et al., 2014). Microsatellites analysed in this study confirmed a high similarity of all Slovak samples, although a significant decrease in allelic diversity for F1 and STOCK groups was recorded. Furthermore, the majority of individuals were well identified to the a priori defined groups. Reinartz et al. (2011), based on similar results, suggested that Danube sterlets form one panmictic population; however, Cvijanović et al. (2017) did not support this statement. In fact, low level of differentiation between sampling sites in combination with low levels of the local diversity could reflect what once was a well-diversified panmictic population but nowadays is represented by its remnants influenced by stocked individuals that originated from the wild population but had very limited genetic diversity. Dudu et al. (2011) observed lower heterozygosity than expected, which could be a sign of loss within the genetic diversity. Additionally, they detected lower levels of polymorphism in microsatellite loci LS19 and LS54, the same loci that were the least polymorphic or even monomorphic in our study. These findings, together with the differences between wild and brood individuals identified within this study, could demonstrate slight but ongoing loss of the genetic diversity in the sterlet population in the Danube River. Cvijanović et al. (2017) and Reinartz et al. (2011) observed higher heterozygosity than expected. This was observed also in our data and it can be attributed to the mixing of previously isolated populations; in the case of sturgeons, it could be the evidence of restocking by individuals originated from various locations. Even though a more thorough analysis of the Danube sterlet population is necessary to confirm suggested negative trends, the results gained in this study could be valuable for better-directed early conservation actions.

The broodstock (F1) and parents of the stocked individuals (STOCK) used in Slovakia were of the same Middle Danube origin. Later, they were divided into two groups belonging to two different owners. Parents of the stocked individuals were supplemented by their offspring, which likely contributed to the loss of polymorphic alleles and reducing genetic variability. Approximately 10 years of restocking management in Slovakia, which has been a short period of significant group separation, has occurred, but it was likely sufficient for the apparent loss of the alleles within F1 and juvenile groups.

Sturgeons have become highly endangered compared to the past. Unfortunately, ongoing habitat alternations, loss of connectivity, pollution or illegal fishing and poaching threaten these species. Nowadays, all 27 recognized sturgeon species are included on the CITES. The situation with Danube sterlets is very similar. The genetic data acquired within recent studies (e.g. Cvijanović et al., 2015; Fopp-Bayat et al., 2015; Chassaing et al., 2016) clearly show that well-managed and urgent actions are needed if we want to prevent their extinction. Among other actions including the restoration of key habitats and reopening of closed migrations routes, a wellmanaged stocking program is needed. If possible, stocked sterlets should have wild parents consisting of as many individuals as possible, and released, spawned individuals should be tagged to prevent their reuse for spawning. The stabilization of the sterlet population in the Danube river by more intensive stocking with fish adapted to local conditions and of wild origin is crucial in the coming years. Without proper actions, it is very likely that the Danube sterlets will 
face reduced adaptability, population persistence and productivity, and, therefore, further population decline in the future.

\section{Supplementary material}

Table S1. List of Acipenser ruthenus samples from SlovakHungarian stretch of the Danube River analysed in this study ( $\mathrm{S}$ - stocked individuals, F - F1 generation individuals, W wild individuals).

Table S2. Detected haplotypes of Acipenser ruthenus. Colours represent different groups of samples corresponding with haplotype networks: red - wild individuals (W), yellow - F1 generation individuals $(\mathrm{F})$, green - stocked individuals $(\mathrm{S})$, blue colour indicates samples from other countries than Slovakia.

The Supplementary Material is available at https://www.kmaejournal.org $/ 10.1051 / \mathrm{kmae} / 2019004 / \mathrm{olm}$.

Acknowledgements. We would like to thank Jana Bozáňová for her help with laboratory work. We would also like to thank Lance Arendt for English corrections of the manuscript. This work was supported by the Slovak Research and Development Agency under the contract No. APVV-0820-12, and the project ITMS 26240220049 funded by ERDF.

\section{References}

Amos W, Balmford A. 2001. When does conservation genetics matter? Heredity 87: 257-265.

Birstein VJ, DeSalle R. 1998. Molecular phylogeny of Acipenserinae. Mol Phylogenet Evol 9: 141-155.

Briolay J, Galtier N, Brito RM, Bouvet Y. 1998. Molecular phylogeny of cyprinidae inferred from cytochrome bDNA sequences. Mol Phylogenet Evol 9: 100-108.

Chassaing O, Desse-Berset N, Hänni C, Hughes S, Berrebi P. 2016. Phylogeography of the European sturgeon (Acipenser sturio): a critically endangered species. Mol Phylogenet Evol 94: 346-357.

Crispo E, Chapman LJ. 2008. Population genetic structure across dissolved oxygen regimes in an African cichlid fish. Mol Ecol 17: 2134-2148.

Cvijanović G, Adnađević T, Lenhardt M, Marić S. 2015. New data on sterlet (Acipenser ruthenus L.) genetic diversity in the Middle and Lower Danube sections, based on mitochondrial DNA analyses. Genetika 47: 1051-1062.

Cvijanović G, Adnađević T, Jarić I, Lenhardt M, Marić, S. 2017. Genetic analysis of sterlet (Acipenser ruthenus L.) populations in the Middle and Lower Danube sections. North West J Zool 13: 34-43.

Doukakis P, Birstein VJ, Ruban GI, DeSalle R. 1999. Molecular genetic analysis among subspecies of two Eurasian sturgeon species, Acipenser baerii and A. stellatus. Mol Ecol 8: S117-S127.

Dudu A, Suciu R, Paraschiv M, Georgescu SE, Costache M, Berrebi P. 2011. Nuclear markers of Danube sturgeons hybridization. Int $J$ Mol Sci 12: 6796-6809.

Dudu A, Georgescu SE, Burcea A, Florescu I, Costache M. 2013. Microsatellites variation in sterlet sturgeon, Acipenser ruthenus from the Lower Danube. Anim Sci Biotechnol 46: 90-94.

Earl DA, vonHoldt, BM. 2012. STRUCTURE HARVESTER: a website and program for visualizing STRUCTURE output and implementing the Evanno method. Conserv Genet Resour 4: 359-361.
Elbrecht V, Feld Ch K, Gies M, HeringD, Sondermann M, Tollrian R, Leese F. 2014. Genetic diversity and dispersal potential of the stonefly Dinocras cephalotes in a central European low mountain range. Freshw Sci 33: 181-192.

Evanno G, Regnaut S, Goudet J. 2005. Detecting the number of clusters of individuals using the software STRUCTURE: a simulation study. Mol Ecol 14: 2611-2620.

Excoffier L, Laval G, Schneider S. 2005. Arlequin (version 3.0): an integrated software package for population genetics data analysis. Evol Bioinform 1: 47-50.

Fopp-Bayat D, Kuzniar P, Kolman R, Liszewski T, Kucinski M. 2015. Genetic analysis of six sterlet (Acipenser ruthenus) populations: recommendations for the plan of restitution in the Dniester River. Iran J Fish Sci 14: 634-645.

Forlani A, Fontana F, Congiu L. 2008. Isolation of microsatellite loci from the endemic and endangered Adriatic sturgeon (Acipenser naccarii). Conserv Genet 9: 461-463.

Friedrich T. 2018. Danube sturgeons: past and future. In: Schmutz S, Sendzimir J, eds. Riverine ecosystem management: science for governing towards a sustainable future, Vol. 8. Berlin: Springer, pp. 507-518.

Guti G, Gaebele T. 2009. Long-term changes of sterlet (Acipenser ruthenus) population in the Hungarian section of the Danube. Opusc Zool Budapest 40: 17-25.

Henderson-Arzapalo A, King TL. 2002. Novel microsatellite markers for Atlantic sturgeon (Acipenser oxyrinchus) population delineation and broodstock management. Mol Ecol Resour 2: 437-439.

Holčík J. 1989. The freshwater fishes of Europe, Vol. 1 (Part II): general introduction to fishes, Acipenseriformes. Wiesbaden: AULA-Verlag.

Holčik J, Klindová A, Masár J, Mészáros J. 2006. Sturgeons in the Slovakian rivers of the Danube river basin: an overview of their current status and proposal for their conservation and restoration. $J$ Appl Ichthyol 22: 17-22.

Horne JB, Momigliano P, Welch DJ, Newman SJ, Van Herwerden L. 2011. Limited ecological population connectivity suggests low demands on self-recruitment in a tropical inshore marine fish (Eleutheronema tetradactylum: Polynemidae). Mol Ecol 20: 2291-2306.

Hubisz MJ, Falush D, Stephens M, Pritchard JK. 2009. Inferring weak population structure with the assistance of sample group information. Mol Ecol Resour 9: 1322-1332.

Ivanova NV, Zemlak TS, Hanner RH, Hebert PD. 2007. Universal primer cocktails for fish DNA barcoding. Mol Ecol Resour 7: 544-548.

Jombart T, Ahmed I. 2011. adegenet 1.3-1: new tools for the analysis of genome-wide SNP data. Bioinformatics 27: 3070-3071.

Jug T, Berrebi P, Snoj A. 2005. Distribution of non-native trout in Slovenia and their introgression with native trout populations as observed through microsatellite DNA analysis. Biol Conserv 123: $381-388$

King TL, Lubinski BA, Spidle AP. 2001. Microsatellite DNA variation in Atlantic sturgeon (Acipenser oxyrinchus oxyrinchus) and cross-species amplification in the Acipenseridae. Conserv Genet 2: 103-119.

Kubala M, Farský M, Pekárik L. 2017. Stocking efficiency of the sterlet (Acipenser ruthenus, Linneaus 1758) in the SlovakHungarian Danube stretch. Sci Eruditio 1: 25-31 (in Slovak with English summary).

Leberg PL, Firmin BD. 2008. Role of inbreeding depression and purging in captive breeding and restoration programmes. Mol Ecol 17: 334-343. 
Leigh JW, Bryant D. 2015. popart: full-feature software for haplotype network construction. Methods Ecol Evol 6: 1110-1116.

Librado P, Rozas J. 2009. DnaSP v5: a software for comprehensive analysis of DNA polymorphism data. Bioinformatics 25, $1451-1452$.

Ludwig A, Belfiore NM, Pitra C, Svirsky V, Jenneckens I. 2001. Genome duplication events and functional reduction of ploidy levels in sturgeon (Acipenser, Huso and Scaphirhynchus). Genetics 158: $1203-1215$.

Lynch M, Conery JS. 2003. The origins of genome complexity. Science 302: 1401-1404.

May B, Krueger CC, Kincaid HL. 1997. Genetic variation at microsatellite loci in sturgeon: primer sequence homology in Acipenser and Scaphirhynchus. Can J Fish Aquat Sci 54: $1542-1547$.

Mugue N, Barmintseva A, Schepetov D, Shalgimbayeva G, Isbekov K. 2016. Complete mitochondrial genomes of the critically endangered Ship sturgeon Acipenser nudiventris from two seas. Mitochondrial DNA B 1: 195-197.

O'Brien SJ. 1994. A role for molecular genetics in biological conservation. Proc Natl Acad Sci USA 91: 5748-5755.

Pauls SP, Nowak C, Balint M, Pfenninger M. 2013. The impact of global climate change on genetic diversity within populations and species. Mol Ecol 22: 925-946.

Peakall ROD, Smouse PE. 2006. GENALEX 6: genetic analysis in Excel: population genetic software for teaching and research. $\mathrm{Mol}$ Ecol Resour 6: 288-295.
Pritchard JK, Stephens M, Donnelly P. 2000. Inference of population structure using multilocus genotype data. Genetics 155: 945-959.

R Core Team. 2017. R: a language and environment for statistical computing. R Foundation for Statistical Computing, Vienna, Austria (retrieved from https://www.R-project.org/).

Reinartz R. 2002. Sturgeons in the Danube River: biology, status, conservation; literature study. IAD.

Reinartz R, Lippold S, Lieckfeldt D, Ludwig A. 2011. Population genetic analyses of Acipenser ruthenus as a prerequisite for the conservation of the uppermost Danube population. J Appl Ichthyol 27: 477-483.

Tamura K, Stecher G, Peterson D, Filipski A, Kumar S. 2013. MEGA6: molecular evolutionary genetics analysis version 6.0. Mol Biol Evol 30: 2725-2729.

Tringali MD, Bert TM. 1998. Risk to genetic effective population size should be an important consideration in fish stock-enhancement programs. Bull Marine Sci 62: 641-659.

Van Oosterhout C, Hutchinson WF, Wills DP, Shipley P. 2004. MICRO-CHECKER: software for identifying and correcting genotyping errors in microsatellite data. Mol Ecol Resour 4: 535-538.

Werle E, Schneider C, Renner M, Völker M, Fiehn W. 1994. Convenient single-step, one tube purification of PCR products for direct sequencing. Nucleic Acids Res 22: 4354.

Zhang X, Wu W, Li L, Ma X, Chen J. 2013. Genetic variation and relationships of seven sturgeon species and ten interspecific hybrids. Genet Sel Evol 45: 21.

Cite this article as: Pekárik L, Čiamporová-Zatovičová Z, Arendt D, Čiampor Jr F. 2019. Current stocking program of the sterlet (Acipenser ruthenus, L.) can negatively shape its genetic variability in the Middle Danube. Knowl. Manag. Aquat. Ecosyst., 420,19 